\title{
When Rats Rescue Robots
}

Laleh K. Quinn ${ }^{1 * \#}$, Luisa P. Schuster ${ }^{1 \#}$, Marcelo Aguilar-Rivera ${ }^{2 \#}$, Joshua Arnold ${ }^{3}$, David Ball ${ }^{3}$, Emmanuel Gygi ${ }^{1}$, Scott Heath ${ }^{3}$, Jesse Holt ${ }^{1}$, Daeun J. Lee ${ }^{1}$, Jonathon Taufatofua ${ }^{3}$, Janet Wiles ${ }^{3}$, and Andrea A. Chiba ${ }^{1}$

${ }^{1}$ Department of Cognitive Science, UCSD, La Jolla, CA, USA

${ }^{2}$ Department of Bioengineering, UCSD, La Jolla, CA, USA

${ }^{3}$ School of Information Technology \& Electrical Engineering, University of Queensland, Queensland, Australia

\#Denotes equal authorship

*Corresponding author (Email: lquinn@ucsd.edu)

Citation - Quinn, L.K., Schuster, L.P., Aguilar-Rivera, M., Arnold, J., Ball, D., Gygi, E., Heath, S., Holt, J., Lee, D.J., Taufatofua, J., Wiles, J., \& Chiba, A.A. (2018). When rats rescue robots. Animal Behavior and Cognition, 5(4), 368-379. https://doi.org/10.26451/abc.05.04.04.2018

\begin{abstract}
Robots are increasingly being used to monitor and even participate in social interactions with animals in their own environments. Robotic animals enable social behaviors to be observed in natural environments, or specifically elicited under the control of an experimenter. It is an open question to what extent animals will form positive social connections with such robots. To test this, we familiarized rats to two rat-sized robots, one exhibiting "social" behaviors, including helping, while the other was also mobile but not helpful. When given an opportunity to release the robots from restrainers, as they do for conspecifics, we found that rats did release the robots, and moreover, were significantly more likely to release the helpful than the unhelpful robot. These findings indicate that robots can elicit helpful behavior from rats, and that rats will even discriminate between robots on the basis of their behaviors.
\end{abstract}

Keywords - Rat, Robot, Reciprocity, Pro-social

The power of social robots - robots that help study and engage in social behavior - lies in their ability to move effectively in an animal's environment, and even to elicit behaviors of interest (Frohnwieser, Murray, Pike, \& Wilkinson, 2016; Le Maho et al., 2014; Macedonia, Clark, Riley, \& Kemp, 2013; Partan, Fulmer, Gounard, \& Redmond, 2010; Partan, Larco, \& Owens, 2009; Partan, Otovic, Price, \& Brown, 2011; Patricelli, Coleman, \& Borgia, 2006; Patricelli, Uy, Walsh, \& Borgia, 2002; Ruberto, Polverino, \& Porfiri, 2017; Rundus, Owings, Joshi, Chinn, \& Giannini, 2007; Veling, 2017). It is easy for an animal to be frightened by a robot and freeze or avoid it (Shi et al., 2011, Shi, Ishii, Kinoshita, Konno, et al., 2013; Shi Ishii, Kinoshita, Takanishi, et al., 2013; Shi, Ishii, Sugahara, et al., 2015; Shi, Ishii, Tanaka, et al., 2015), but can a robot be accepted as a benign companion, or even elicit pro-social behaviors, such as behaviors that provide help or comfort, from an animal? Although the definition of "pro-social" is broad, many types of pro-social behavior involve cooperation (working together to achieve a goal), reciprocity (paying back to the agent who helped them or paying forward after being helped,), and helpful action, including performing a set of actions that confer an alleviation of distress (Eisenberg et al., 1989). For example, humans feel obligated to "return the favor" towards a specific individual when an act of kindness is directed towards them (Watanabe et al., 2014), and will exert effort to help others in need of help (Fehr \& Fischbacher, 2003; Sober \& Wilson, 1998). Recent work on reciprocity and helping, in the sense of alleviating distress, has revealed that these types of pro-social behavior are not limited to humans, but are found in many cooperative species including reciprocal food sharing in hyenas (Owens \& Owens, 1984), ravens (Heinrich \& Marzluff, 1995) and vampire bats (Wilkinson, 1984), allomothering in African elephants (Lee, 1987) and long-tailed tits (Hatchwell, Gullett, \& Adams, 2013), directed rescue behavior 
in ants (Nowbahari, Scohier, Durand, \& Hollis., 2009), tool provision in chimpanzees (Yamamoto et al., 2013, consoling behavior in bonobos (Clay \& de Waal, 2013), and cooperation, reciprocity, and helping in rodents (Ben-Ami Bartal, Decety, \& Mason, 2011, Ben-Ami Bartal, Rodgers, Bernardez Sarria, Decety, \& Mason, 2014; Rutte \& Taborsky, 2007a, b; Sato, Tan, Tate, \& Okada, 2015).

In fact, rodents seem to make complicated appraisals concerning the nature and extent of help that has been extended to them. For example, rats will help unrelated rats more if the unrelated rats were previously helpful to them, than if they did not offer help, indicating they have a form of "direct" reciprocity (Rutte \& Taborsky, 2007a; Roberts, 2008; Trivers, 1971). Additionally, if given a choice, rats will select an alternative that results in food reward for both themselves and a partner, rather than themselves alone, suggesting that they are capable of displaying food sharing, a behavior that is often considered a form of generosity (Hayes, Ullman, Alexander, Bank, \& Scassellati, 2014). There is even some evidence that rats show a form of indirect reciprocity (Alexander, 1987), and will "pay it forward," by rewarding an unknown, unrelated rat that has never rewarded them, but only if they have experienced reward previously provided by other rats (Rutte \& Taborsky, 2007b). Rats have also been shown to release a trapped cage mate from a restrainer and from an enclosure of water, possibly indicating a form of empathy, which may be defined as the ability to affectively discern the distress of another (Ben-Ami Bartal et al., 2014; Sato et al., 2015). Whereas such pro-social behavior seems clearly to exist between rats, it is an open question whether any type of pro-social behavior could extend to a completely alien being such as a robot, and if so, under what conditions. If rats do act pro-socially towards robots this would greatly enhance the conditions under which robots may be used as tools to study social behavior. The ability to control for one or a few variables, such as movement, allows for an increased likelihood in discovering the sufficient conditions under which prosociality may be elicited. And while it has been shown that rats will extend pro-social behaviors towards non-kin and even to different strains of rats (Ben-Ami Bartal et al., 2014), if they are to do so towards artificial entities, this would provide insight into how such extension occurs.

There is a long history of the effect of movement on sociality; animacy and intentionality can be read even from the movement of simple shapes (Barrett, Todd, Miller, \& Blythe, 2005; Heider \& Simmel, 1944; Lasseter, 2001; Thomas \& Johnston, 1995), of other non-human forms (Blythe, Todd, \& Miller, 1999), and even by infants (Jones \& Davis, 1965). Recent studies have shown that intentions can be communicated and emotions can be evoked purely through observing the way robots move. This is made particularly evident in the work of Hoffman (2013), and Hoffman and Ju (2014) who showed that, like the Pixar lamp animation (Lasseter, 1986), inanimate objects can be considered animate if the proper movements, and especially the temporal dynamics of the movements, are displayed through the intentions of the human animating it (Hamlin, Wynn, \& Bloom, 2007). Thus, it is possible that, through movement alone, rats will differentiate between two robots and treat them in a distinct manner.

To test whether rats display pro-social behaviors toward an artificial agent, we examined their inclination to help a robot that previously interacted with and helped them. Pairs of rats were initially observed and video recorded while in an enriched environment, so as to learn the types of social interactions frequently displayed among them. The rats were then trained to open the door of an enclosure that held their trapped cage mate. Once they learned to open the door, they were introduced to two similar, but visually and olfactorally distinct robots. The two rats and two robots were placed in the enriched environment with several objects to play with. One of the robots was deemed the social robot, engaging in rodent-like social behaviors including following, mirroring, exploring, and playing with toys. This was done through experimenter manipulation of the robot's movement alone. The other robot was mobile, but expressed only minimal behaviors such as moving forwards and backwards and side to side (Video 1).

After the rats became familiar with the robots in the enriched environment, each rat was trapped in the enclosure, and was released by the helpful robot three times while the other robot performed random movements in the arena (Video 2). The rats were then given the opportunity to open the door of two enclosures, one that trapped the helpful robot and one that trapped the unhelpful robot (Figure 1). Our hypothesis was that the rats would release both robots given that both of the robots were highly familiar, and that opening doors may have been somewhat reinforcing, but would show preferential opening behavior to the robot that was social and helpful. 


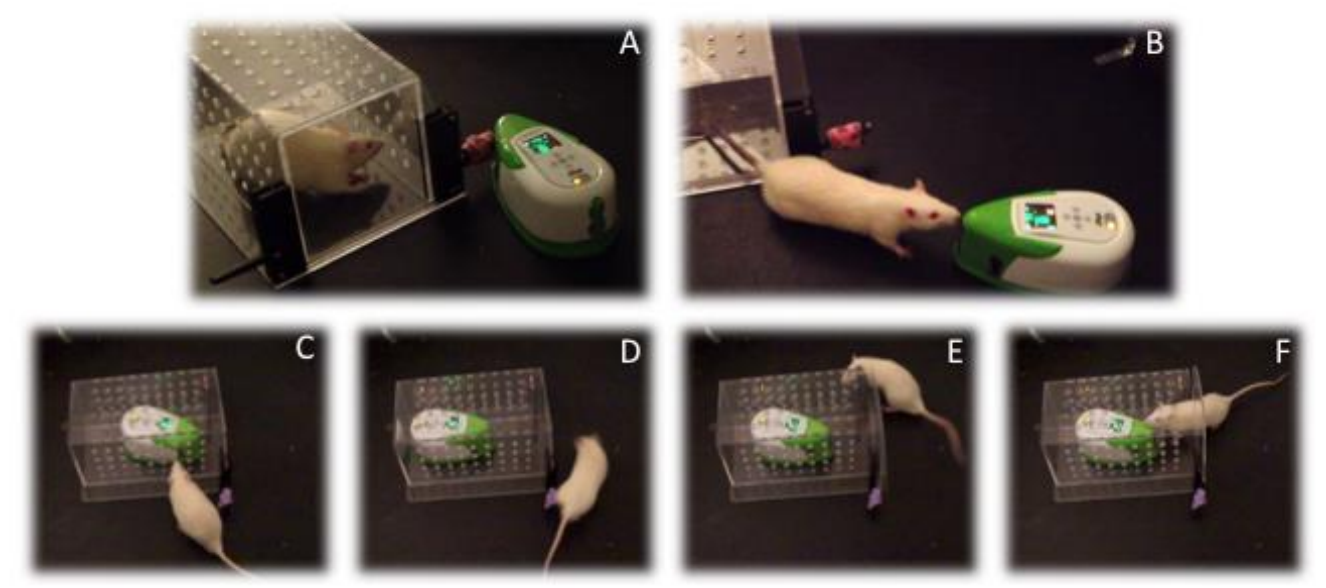

Figure 1. Storyboard of a typical rat's behavior with the helpful robot. A. The helpful robot pushes the lever to release a rat from the restrainer. B. A typical nose to "nose" check from the rat following robot opening the door. C. A rat viewing the helpful robot trapped in the restrainer. D. The rat moves directly from viewing the trapped robot to side of the restrainer where the lever is located. E. The rat presses the lever to open the door for the helpful robot (note the gaze of the rat towards the robot). F. The rat interacts with the robot immediately following door opening.

\section{Methods}

\section{Animals and Housing}

All animal procedures were performed in accordance with National Institutes of Health $(\mathrm{NIH})$ and local Institutional Animal Care and Use (IACUC) guidelines. Eight adult, male Sprague-Dawley rats (Harlan Laboratories) were used as subjects. Beginning at 6 weeks old, the rats were housed in pairs and maintained on a $12 \mathrm{~h}$ light/dark cycle. Rats were chosen to be housed together in pairs as it has been previously shown that rats will release other rats from enclosures if they live in a dyadic environment (BenAmi Bartal et al., 2011). They were acclimated to the colony room for 5 days, during which they had $a d$ libitum access to food and water. The rats were handled daily for 1.5 weeks before beginning the experiment. Rats were 8 weeks old when the experiment began. All behavioral testing occurred during the rats' light cycle.

\section{Robots, Enriched Environment, and Restrainer}

Robots. Two wheeled robots (Wiles, et al., 2012) were used in this experiment. Each robot had dimensions $180 \mathrm{~mm}(\mathrm{~L}) \times 100 \mathrm{~mm}(\mathrm{~W}) \times 70 \mathrm{~mm}(\mathrm{H})$ and weighed $0.6 \mathrm{~kg}$, with a run time of $120 \mathrm{~min}$ powered by a rechargeable Li-Ion battery. The two robots differed in color: one was white with green markings, and the other was white with red markings. Because red and green may be difficult for rats to disambiguate, the red robot also had several pieces of paper adhering to the body case to make it visually distinguishable from the green robot.

For the purposes of this experiment, the red robot was programmed to act in a repetitive manner that was not supposed to be conducive to social interaction. Such behaviors included: looping around the same area and repetitive backward and forward or side-to-side motion. Conversely, the green robot was controlled remotely by the experimenter (known as the Wizard of Oz (WoZ) technique in robotics (Kelley, 1984; Riek, 2012) in order to respond to the social demands of the environment in real time. The wheeled locomotion of both robots was limited to $\sim 0.5 \mathrm{~m} / \mathrm{s}$.

In order to further differentiate the robots, and to account for the Sprague Dawley's low spectral acuity (Jacobs, 1993) and high olfactory sensitivity, a small cotton pad $(2.5 \mathrm{~cm} \mathrm{x} 2.5 \mathrm{~cm})$ was daubed with myrrh essential oil (Healing Solutions, Scottsdale, AZ) and placed in the hindmost portion of the green robot under its plastic shell. The same was done for the red robot, this time with frankincense essential oil 
(Healing Solutions, Scottsdale, AZ). These two odors were chosen due to their equivalent preference profiles (Geoffrey Schoenbaum, personal communication) and inclusion in the same category of odor (woody). However, to ensure that rats do not show preference for one of the odors over the other, we performed an olfactory preference task.

Enriched Environment Arena. A concentric plastic arena (114 cm total diameter), with an outer track $(10 \mathrm{~cm})$ separated by an inner wall $(13 \mathrm{~cm}$ height $)$ and surrounded by an outer wall $(8 \mathrm{~cm}$ height $)$, was used during testing. A circular sheet of Plexiglas $(97 \mathrm{~cm})$ was put atop of the inner arena to ensure smooth movement of the robot. The enriched environment (EE) consisted of seven store-bought toys for rodents, some or all of which were used on a given day. The toys were randomly distributed by the experimenter, but placed in a manner that would allow for free movement around the arena by both the rats and the robots.

Restrainer. Two identical custom designed Plexiglas restrainers $(15.3 \mathrm{~cm}$ x $29.2 \mathrm{~cm} \times 15.3 \mathrm{~cm} \mathrm{JM}$ Specialty Parts, San Diego, CA) were used in the experiment. The size of the restrainer allowed the rat to move around freely within it and allowed for the robots to fit inside. The lateral and top walls of the restrainer each had 36 circular openings $(1 \mathrm{~cm}$ diameter holes) that allowed for multimodal interaction between the rats. The door of the restrainer contained no holes and was controlled by a lever located on the left of the restrainer. The door would open to the side if enough pressure was applied to the lever. A metal weight $(50.3 \mathrm{~g})$ was strapped to the lever to facilitate door opening. Typically, the lever was activated when the rat would press it with one or both forepaws; however, instances in which rats opened the door by pressing the lever with other body parts happened on occasion. The restrainers were placed in the concentric arena after the enriched environment session was over and the toys were removed.

\section{Experimental Procedure}

Habituation to enriched environment phase. In order to habituate the rats to the environment, paired rats were placed in the enriched environment arena for $30 \mathrm{~min}$ on days 1- 4 and $20 \mathrm{~min}$ on days 511 to allow for acclimation to the enriched environment and to the room they would be tested in. Interactions with the environment, and each other, were observed and recorded.

Restrainer training phase. On days 12-38, rat pairs were initially placed in the enriched environment and allowed to explore it for $15 \mathrm{~min}$ on days 12-20 and for $10 \mathrm{~min}$ from day $21 \mathrm{on}$. After the enriched environment, the rats were returned to their cages, while the toys were cleared from the arena and a restrainer was placed against the inner wall of the concentric surface. A barrier was placed around the inner wall of the outer track to circumscribe the testing arena. Afterwards, one of the rats in the pair was marked with non-toxic ink. The rat with no markings was placed in the Plexiglas restrainer (trapped rat), while the marked rat was placed outside (partner rat). The partner rat was allowed $300 \mathrm{~s}$ to open the restrainer. If the partner rat failed to open the restrainer during the allocated time, the trapped rat was released from the restrainer to avoid excessive distress. In order to eliminate potential odor and cuing effects, an experimenter used a tool (long thin rod) to press the lever from a point where the rat could not see the experimenter. The rats were allowed to interact for $60 \mathrm{~s}$ after the door was opened. Afterwards, the trapped rat was placed back in the restrainer and a new trial began. Every three trials, the rats swapped roles. The rats performed a total of 35 trials. This was sufficient to indicate learning of the task contingencies (that pressing the lever resulted in opening the restrainer door) in all of the rats that were tested, each having reached a criterion of $80 \%$ opening for their partner.

Introduction of robots in the enriched environment arena. On day 39, the two robots were introduced in the enriched environment arena with both rats simultaneously. The "social" robot was controlled remotely, by the experimenter, to follow the rats as they played and also to interact with the toys, with which the rats were engaging. In the meantime, the "asocial" robot, repeatedly made back and forth and side to side movements. This occurred for four consecutive days, until each rat became fully adjusted to the robot and no longer showed any freezing behavior in their presence.

Rats initially were fearful of the robots, peering out at them from a safe location. Because of this, during early encounters in the environment, the social robot, was guided to show non-threatening types of behaviors such as backing up when the rats peered at it and never directly following. During this period, 
the experimenter manipulated the robot in a way that the rats would not become permanently frightened of the robots, for example by not getting too close to the rats, or by backing up the robot when the rats appeared frightened. When rats were more comfortable with the robots, the social robot was controlled in such a way as to indicate sociality. To achieve this, robotic movement included following the rats from a far enough distance so as not to be threatening, mirroring (for example, going to the same objects as the rats) and interacting with the toys, as well as simple individualistic movement around the environment.

Exposure to the "social" and "asocial" robots in the restrainer condition. On day 43, the paired rats were placed in the enriched environment along with the robots. After $10 \mathrm{~min}$, the rats were returned to their cages while the toys were cleared from the arena and the restrainer was placed against the inner wall of the concentric surface. The barrier was also installed to ensure the rats could not see the experimenters. One of the paired rats was placed inside the restrainer and both robots were placed in the arena. After spending $30 \mathrm{~s}$ in the restrainer, the trapped rat was released by the helpful robot. The helpful robot was controlled by the experimenter, who was observing the experiment through a video monitor, and would press the lever only when the trapped rat was looking at it. In the meantime, the unhelpful robot, was also visible and performed very minor movements while the door was opened, then began its normal random movements. The rat was allowed to interact with the robots and the environment for $60 \mathrm{~s}$ and then placed back in the restrainer. After three trials, the rat was returned to his cage.

Behavioral recordings. To monitor and record behavior, a monochrome CCTV video camera (Panasonic WV-BP332) was placed above the experimental arena and a polychrome digital video camera (Canon Vixia HFG10) was situated next to it. The monochrome camera was linked via a video card to a PC exclusively allocated for this experiment.

Preference test with robots in restrainers. In order to examine whether there was a preference to open the restrainer for the robot that performed helpful and "social" actions over the randomly moving robot, immediately following the arena experiment, each of the rats separately performed the following preference test. Two identical restrainers were placed in the arena, each containing one of the robots. One of the paired rats was put in the arena and allowed $120 \mathrm{~s}$ to open the restrainer(s). The times of opening were recorded. If the rat opened the restrainer, it was allowed to remain in the arena and interact with the robots for $60 \mathrm{~s}$. The rat was then taken out of the arena, the robots swapped restrainers, the restrainers were positioned in a different location within the arena, and a new trial started. After three trials, the rat was returned to his cage. This experimental procedure was repeated once a day for 6 days.

Odor preference control task. Twelve male Sprague-Dawley rats, that were not used in the main experiment, were used for the odor preference task. In order to determine whether rats show a preference for either Frankincense or Myrrh, we performed an odor preference task on rats naïve to the different odors. Three saltshakers filled with black sand were infused with drops of either frankincense, myrrh, or mineral oil (the latter serving as a control). Each rat underwent six, 1-minute trials. Two trials of mineral oil, two trials of myrrh oil and two trials of frankincense oil were presented within a cage and randomized in order. The mean time each rat spent actively sniffing the saltshaker was calculated. This was done for two days for a total of 12 trials per rat.

\section{Statistical Methods}

On a given trial, the rat could 1) open the door for only the helpful robot 2) open the door for only the unhelpful robot, 3) open the door for both robots, or 4) not open any doors on that trial. Analyses were based on values from 6 days ( 3 trials per day) for eight rats. Thus, door opening for each rat was calculated as a probability across 18 trials of the experiment. Given that the number and duration of interactions between each pair of rats and the robots were not collinear, and that the rats were tested individually (without their cage mate), we considered each rat as a unit. Thus, the number of samples for each of the above statistical comparisons was eight.

Opening for robots. Here we looked at the probability of opening for robots generally, which includes opening for helpful only, opening for unhelpful only, and opening for both, within a given trial. 
Opening for helpful robot. We then proceeded to test the hypothesis that rats would demonstrate a preference for a robot that exhibited helpful behavior. To test this hypothesis, we used one-tailed Wilcoxon signed rank test (MATLAB, Mathworks) comparing the probability of opening the door for the helpful robot vs. the unhelpful robot regardless of which one was opened first, or if rats opened for only one robot.

Additionally, we quantified whether each rat opened more (signified by a greater number of total door openings) for a given robot (helpful or unhelpful).

Opening for the helpful robot only. We then tested the hypothesis that rats opened more frequently for the helpful robot. We looked at the cases where rats opened only for one robot and compared the probability of opening for the helpful robot vs the unhelpful robot.

We used one-tailed Wilcoxon signed rank test (MATLAB, Mathworks) to compare the probability of opening a door for only the helpful robot as compared to the probability of opening a door for only the unhelpful robot.

\section{Results}

Rats clearly engaged in opening doors for robots (Figure 2A). Rats opened the doors for at least one robot $76.4 \%$ of the time they had the opportunity. The remaining $23.6 \%$ of the time, they opened no doors.

Rats also demonstrated a significant preference for the helpful robot over the unhelpful robot (despite often opening the door for both). One-tailed Wilcoxon signed rank test comparing the probability of opening the door for the helpful robot vs. the unhelpful robot (please note, that this is door opening in general and it was possible to open the door for both) revealed a significant difference ( $W=33 ; p=.019$; median $=0.528$ (helpful), 0.472 (unhelpful)). This preference for door opening is depicted in Figure 2B (also see Video 3). Additionally, seven of eight rats demonstrated a greater number of openings for the helpful robot and one rat demonstrated a greater number of openings for the unhelpful robot, as depicted in Figure 2C.

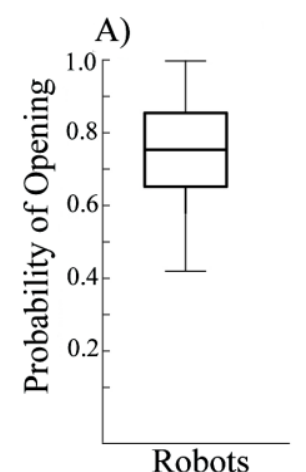

Robots
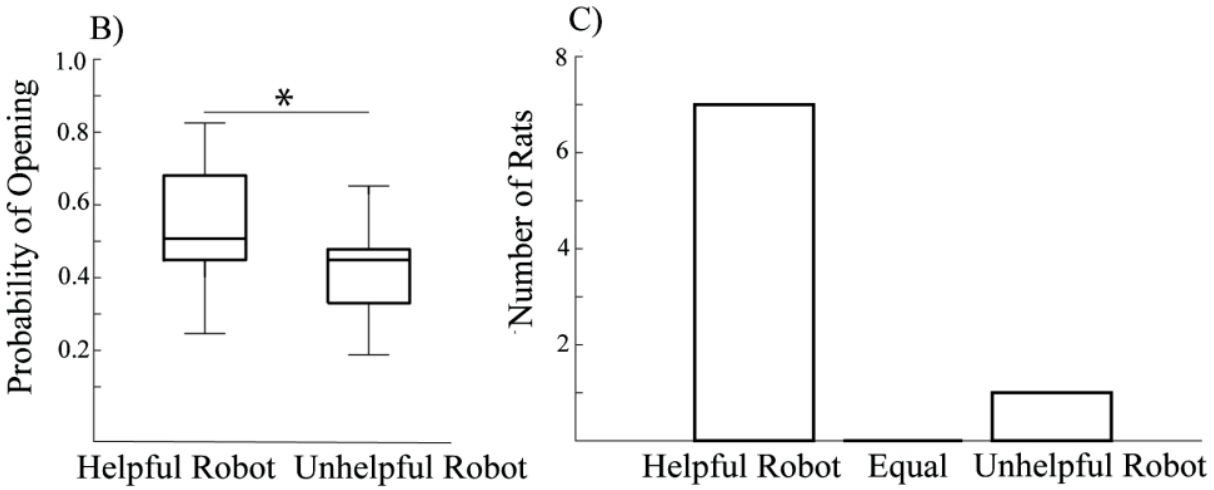

Figure 2. A) Rats frequently open for robots who are trapped in an enclosure. Center line $=$ median. Top $=75^{\text {th }}$ percentile, bottom $=25^{\text {th }}$ percentile B) Rats often open doors for both the helpful and unhelpful robot. However, they exhibited a preference for opening doors for the helpful robot. Center line $=$ median. Top $=75^{\text {th }}$ percentile, bottom $=25^{\text {th }}$ percentile $\left.* p<.05 \mathbf{C}\right)$ Seven out of eight rats opened more frequently for the helpful robot.

In observing the probability of opening only for the helpful robot as compared to only for the unhelpful robot (in cases where they did not open for both), it became evident that there was a strong preference to open only for the helpful robot (see Figure 3). The results of the one-tailed Wilcoxon sign rank test on the empirical data (MATLAB, Mathworks) comparing the probability of opening a door for only the helpful robot as compared to the probability of opening a door for only the unhelpful robot was significant $(W=32.5 ; p=.023$; median $=0.295$ (helpful) 0.194 (unhelpful). 


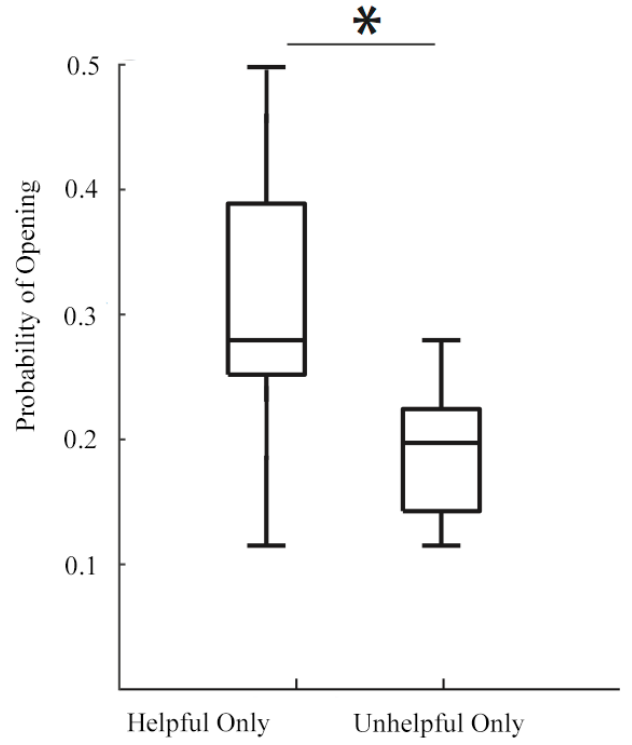

Figure 3. When rats open only for one robot in a given trial, they are more likely to open the door for the helpful robot than the unhelpful robot. Center line $=$ median. Top $=75^{\text {th }}$ percentile, bottom $=25^{\text {th }}$ percentile. $*^{*} p .05$.

Differences between sniffing times for the three odors were non-significant. (Friedman test $p$ $=.904)$. This is taken to indicate that the rats had no basic preference for any of the three odors tested (Figure 4).

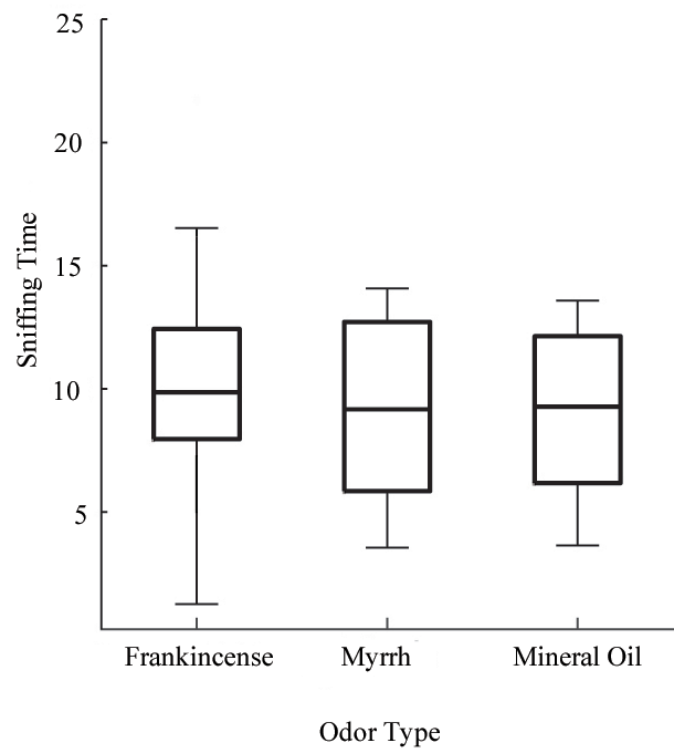

Figure 4. Odor preference task. Pairwise comparisons were made between Frankincense, Myrrh, and Mineral oil. There were no significant differences between sniffing times of any of the three odors presented to the rats. Y-axis units are in seconds. Center line $=$ median. Top $=75^{\text {th }}$ percentile, bottom $=25^{\text {th }}$ percentile. $* p<.05$. 


\section{Discussion}

Although the nascent field of social robotics has made important advancements in human/robot prosocial interactions (Hayes et al., 2014), and there is some evidence that children consider robots as social beings (Meltzoff, Brooks, Shon, \& Rao, 2010; Scassellati, Admoni, \& Matarić, 2012; Tanaka, Cicourel, \& Movellan, 2007), this is the first study to suggest that rats can show pro-social-like behaviors toward artificial entities. It is particularly important because of the minimal design of the robots. The robots were approximately the size of a real rat but had no other features in common with them. Specifically, the robots had no facial features, did not have legs or a tail, did not release pheromones or distress calls, and did not move in a biologically natural way. Social interaction was stimulated solely through types of movement that signified either social engagement or embodied helpful acts by opening the restrainers. During the enriched environment period, an experimenter controlled the robotic rat to mimic the types of behaviors that rats display toward each other and toward the inanimate objects within their environment. Here, the experimenter is essential not just to control the robot in the moment, but also to observe the rats and predict the interaction dynamics for proper short-term timing. Such WoZ control is used widely in robotics in order to have sufficient influence over the robotic behavior required for the task at hand (Reik, 2012).

When given the opportunity, rats released the robots from the restrainers. Importantly, the rats' opening behavior was different for the two robots whose movements and actions were differentially "social". This indicates that the social-like movements of the robot were sufficient to elicit preferential behavior towards it. That the rats showed a preference between the two robots suggests that, along with humans, rats are susceptible to the way in which inanimate objects can become animated through the experimenters' understanding of affect and sociality. The Wizard of Oz technique was used to animate the robots in the hope that the human eye could approximate a social counterpart. In doing so, it may have conferred some characteristics, providing a form of animacy to the rat that altered the rats' behavior. The robot-rat interactions differ from previous studies, at a functional level, as the simple movements of the robots did not just convey intention or emotion, but also effected the first embodied helpful acts by opening the restrainers, providing the opportunity to address the extent to which rats impart pro-sociality to an artificial being.

Numerous studies indicate that rats show a variety of behaviors towards each other that suggest pro-sociality, including reciprocity of different types (Rutte \& Taborsky, 2007a, b) and even altruism (Rice \& Gainer, 1962; Wrighten \& Hall, 2016) and empathy (Atsak et al., 2011; Ben-Ami Bartal et al., 2011; Sato et al., 2015). Whereas these studies point to possible altruism between rats, it is extremely difficult to assess this in any study given the lack of ability to query the animals on the motivations behind their actions. Even in humans, where we can obtain verbal reports of whether they are acting altruistically, motivations can be misattributed and introspection unreliable (Nisbett \& Wilson, 1977).

Moreover, in some of the previous studies where rats released other rats from restrainers (Ben-Ami Bartal et al., 2011), or from water (Sato et al., 2015), the interactions that followed the release of the trapped rat could have acted as a reinforcing event for the "helpful" rat (Vasconcelos, Hollis, Nowbahari, \& Kacelnik, 2012). The opening behavior could be explained by a need to be in proximity to the conspecific, rather than the expression of empathy or altruism towards it. (Schwartz, Silberberg, Casey, Kearns, \& Slotnick, 2017, but see Ben-Ami Bartal et al., 2014 for a strong control on the issue of proximity). In our study, rats had already learned to open the door for their cage mates prior to being introduced to the robots, so their behavior towards the robots may also have been due to a conditioned response realized from the fact that previous openings were reinforcing (Burkart, Fehr, Efferson, \& van Schaik, 2007; MarshallPescini, Dale, Quervel-Chaumette, \& Range, 2016). Although we cannot rule out this possibility, it is important that the rats found releasing the robots reinforcing; moreover, it does not explain why the rats distinguished between the two robots. The fact that the "helpful" robot released them and showed "social" behaviors towards them may have been sufficient for the rats to exhibit preference for that robot and extend their opening behavior to the other robot as well, albeit at a significantly reduced level. Although our experiment has not fully answered the question of reciprocity it is consistent with previous work on reciprocity in conspecifics. As described above, rats show both direct and indirect reciprocity towards other 
rats. In our experiment, the differential responses to the two robots may indicate that the rats are showing a form of direct reciprocity to the helpful robot and indirect reciprocity (of the pay it forward type) to the unhelpful robot as they do with conspecifics (Rutte \& Taborsky, 2007a, b). However, further experiments need to be done to fully understand whether rats in fact show reciprocity to robots and, if so, what type.

As technology invades social ecosystems, it is essential to learn how far social behaviors extend to artificial life forms and conversely, the extent to which artificial life forms affect social culture. This has implications for robot design, because, as robots become social actors, their behavior has the potential to impact - both positively and negatively - cultural norms. The restrained robot task suggests that rats can extend prosocial-like behaviors towards robots, and, moreover, that the robot's behaviors influence the extent of these behaviors in the rats. Pro-social behaviors are essential for the survival of most species, and are so pervasive that, in many animals as well as humans, they extend beyond conspecifics to other species. The increased opening behavior elicited by the "social" and helpful robot as compared to its randomly behaving counterpart indicates that even rats can demonstrate pro-social behavior that extends considerably beyond kinship.

\section{Acknowledgements}

We would like to thank Gabe Schamberg for helpful discussions on the manuscript. This work was supported by an NSF Science of Learning Center Grant SBE0542013 to the Temporal Dynamics of Learning Center, the Australian Research Council Special Research Initiative on Thinking Systems and a Kavli Institute for Brain and Mind Innovative Research Award.

\section{References}

Alexander R. (1987). The biology of moral systems. New York, NY: Aldine De Gruyter.

Atsak, P., Orre, M., Bakker, P., Cerliani, L., Roozendaal, B., Gazzola V., ...Keysers, C. (2011). Experience modulates vicarious freezing in rats: A model for empathy. PLoS One, 6, e21855. http://dx.doi.org/10.1371/journal.pone.0021855

Barrett, H. C., Todd, P. M., Miller, G. F., \& Blythe, P. W. (2005). Accurate judgments of intention from motion cues alone: A cross-cultural study. Evolution and Human Behavior, 26, 313-331. http://dx.doi.org/10.1016/j.evolhumbehav.2004.08.015

Ben-Ami Bartal, I., Decety, J., \& Mason, P. (2011). Empathy and pro-social behavior in rats. Science, 334, 14271430. http://dx.doi.org/10.1126/science.1210789

Ben-Ami Bartal, I., Rodgers D. A., Bernardez Sarria M. S., Decety J., \& Mason P. (2014). Pro-social behavior in rats is modulated by social experience. eLife, 3, e01385. http://dx.doi.org/10.7554/eLife.01385

Blythe, P. W., Todd, P. M., \& Miller, G. F. (1999). How motion reveals intention: Categorizing social interactions. In G. Gigerenzer and P. M. Todd \& The ABC Research Group (Eds.), Evolution and cognition. Simple heuristics that make us smart (pp. 257-285). New York: Oxford University Press.

Burkart, J. M., Fehr, E., Efferson, C., \& van Schaik, C. P. (2007). Other-regarding preferences in a non-human primate: Common marmosets provision food altruistically. Proceedings of the National Academy of Sciences, 104, 19762-19766. http://dx.doi.org/10.1073/pnas.0710310104

Clay, Z., \& de Waal, F. B. M. (2013). Bonobos respond to distress in others: Consolation across the age spectrum. PLOS ONE, 8, e55206. http://dx.doi.org/10.1371/journal.pone.0055206.

Eisenberg, N., Miller, P. A., Schaller, M., Fabes, R. A., Fultz, J., Shell, R., Shea, C. L. (1989) The role of sympathy and altruistic personality traits in helping: a reexamination. Journal of Personality, 57, 41-67.

Fehr, E., \& Fischbacher, U. (2003). The nature of human altruism. Nature, 425, 785-791. http://dx.doi.org/10.1038/nature02043

Frohnwieser, A., Murray, J. C., Pike, T. W., \& Wilkinson, A. (2016). Using robots to understand animal cognition. Journal of the Experimental Analysis of Behavior, 105, 14-22. http://dx.doi.org/10.1002/jeab.193

Hamlin, J. K., Wynn, K., \& Bloom, P. (2007). Social evaluation by preverbal infants. Nature, 450, 557-559. http://dx.doi.org/10.1038/nature06288 
Hatchwell, B. J., Gullett, P. R., \& Adams, M. J. (2014). Helping in cooperatively breeding long-tailed tits: a test of Hamilton's rule. Philosophical Transactions of the Royal Society B: Biological Sciences, 369, 20130565. http://doi.org/10.1098/rstb.2013.0565

Hayes, B., Ullman, D., Alexander, E., Bank, C., \& Scassellati, B. (2014). People help robots who help others, not robots who help themselves. The 23rd IEEE International Symposium on Robot and Human Interactive Communication. http://dx.doi.org/10.1109/roman.2014.6926262

Heider, F., \& Simmel, M. (1944). An experimental study of apparent behavior. The American Journal of Psychology, 57, 243-259. http://dx.doi.org/10.2307/1416950

Heinrich, B., \& Marzluff, J. (1995). Why ravens share. American Scientist, 83, 342-349.

Hoffman, G., \& Ju, W. (2014). Designing robots with movement in mind. Journal of Human-Robot Interaction, 3 , 89-122. http://dx.doi.org/10.5898/jhri.3.1.hoffman

Hoffman, G. (2013). Evaluating fluency in human-robot collaboration. In International conference on human-robot interaction (HRI), workshop on human robot collaboration (Vol. 381, pp. 1-8).

Jacobs, G. H. (1993). The distribution and nature of colour vision among the mammals. Biological Reviews, 68, 413471. http://dx.doi.org/10.1111/j.1469-185x.1993.tb00738.x

Jones, E. E., \& Davis, K. E. (1965). From acts to dispositions: The attribution process in person perception. Advances in Experimental Social Psychology, 2, 219-266. http://dx.doi.org/10.1016/s0065-2601(08)60107-0

Kelley, J. F. (1984). An iterative design methodology for user- friendly natural language office information applications. ACM Transactions on Information Systems, 2, 1, 26-41. http://dx.doi.org/10.1145/357417.357420

Lasseter, J. (2001). Tricks to animating characters with a computer. ACM SIGGRAPH Computer Graphics, 35, 4547. http://dx.doi.org/10.1145/563693.563706

Lasseter, J. (1986). Luxo Jr. Pixar Animation Studios. Pixar. Available from http://www.pixar.com/short films/Theatrical-Shorts/Luxo-Jr.

Le Maho, Y. L., Whittington, J. D., Hanuise, N., Pereira, L., Boureau, M., Brucker, M., . . B ohec, C. L. (2014). Rovers minimize human disturbance in research on wild animals. Nature Methods, 11, 1242-1244. http://dx.doi.org/10.1038/nmeth.3173

Lee, P. C. (1987). Allomothering among African elephants. Animal Behaviour, 35, 278-291. http://dx.doi.org/10.1016/S0003-3472(87)80234-8

Macedonia, J. M., Clark, D. L., Riley, R. G., \& Kemp, D. J. (2013). Species recognition of color and motion signals in Anolis grahami: Evidence from responses to lizard robots. Behavioral Ecology, 24, 846-852. http://dx.doi.org/10.1093/beheco/art027

Marshall-Pescini, S., Dale, R., Quervel-Chaumette, M., \& Range, F. (2016). Critical issues in experimental studies of prosociality in non-human species. Animal Cognition, 19, 679-705. http://dx.doi.org/10.1007/s10071-0160973-6

Meltzoff, A. N., Brooks, R., Shon, A. P., \& Rao, R. P. (2010). "Social” robots are psychological agents for infants: A test of gaze following. Neural Networks, 23, 966-972. http://dx.doi.org/10.1016/j.neunet.2010.09.005

Nisbett, R. E., \& Wilson, T. D. (1977). Telling more than we can know: Verbal reports on mental processes. Psychological Review, 84, 231-259. http://dx.doi.org/10.1037/0033-295X.84.3.231

Nowbahari, E., Scohier, A., Durand, J.-L., \& Hollis, K. L. (2009). Ants, Cataglyphis cursor, use precisely directed rescue behavior to free entrapped relatives. PLOS ONE, 4, e6573. http://dx.doi.org/10.1371/journal.pone.0006573

Owens D.D., \& Owens M.J. (1984). Helping behaviour in brown hyenas. Nature, 308, 843-845

Partan, S. R., Fulmer, A. G., Gounard, M. A., \& Redmond, J. E. (2010). Multimodal alarm behavior in urban and rural gray squirrels studied by means of observation and a mechanical robot. Current Zoology, 56, 313-326.

Partan, S. R., Larco, C. P., \& Owens, M. J. (2009). Wild tree squirrels respond with multisensory enhancement to conspecific robot alarm behaviour. Animal Behaviour, 77, 1127-1135. http://dx.doi.org/10.1016/j.anbehav.2008.12.029

Partan, S. R., Otovic, P., Price, V. L., \& Brown, S. E. (2011). Assessing display variability in wild brown anoles Anolis sagrei using a mechanical lizard model. Current Zoology, 57, 140-152. http://dx.doi.org/10.1093/czoolo/57.2.140

Patricelli, G. L., Coleman, S. W., \& Borgia, G. (2006). Male satin bowerbirds, Ptilonorhynchus violaceus, adjust their display intensity in response to female startling: An experiment with robotic females. Animal Behaviour, 71, 49-59. http://dx.doi.org/10.1016/j.anbehav.2005.03.029

Patricelli, G. L., Uy, J. A., Walsh, G., \& Borgia, G. (2002). Male displays adjusted to females response. Nature, 415, 279-280. http://dx.doi.org/10.1038/415279a 
Rice, G.E. \& Gainer, P. (1962) "Altruism" in the Albino Rat. Journal of Comparative and Physiological Psychology, 55, 123-125. https://doi.org/10.1037/h0042276

Riek, L. D. (2012). Wizard of Oz studies in HRI: A systematic review and new reporting guidelines. Journal of Human-Robot Interaction, 1, 119-136. http://dx.doi.org/10.5898/jhri.1.1.riek

Roberts, G. (2008). Evolution of direct and indirect reciprocity. Proceedings of the Royal Society of London B: Biological Sciences, 275, 173-179. http://dx.doi.org/10.1098/rspb.2007.1134

Ruberto, T., Polverino, G., \& Porfiri, M. (2017). How different is a 3D-printed replica from a conspecific in the eyes of a zebrafish? Journal of the Experimental Analysis of Behavior, 107, 279-293. http://dx.doi.org/10.1002/jeab.247

Rundus, A. S., Owings, D. H., Joshi, S. S., Chinn, E., \& Giannini, N. (2007). Ground squirrels use an infrared signal to deter rattlesnake predation. Proceedings of the National Academy of Sciences, 104, 14372-14376. http://dx.doi.org/10.1073/pnas.0702599104

Rutte, C., \& Taborsky, M. (2007a). Generalized reciprocity in rats. PLoS Biology, 5, 1421-1425. http://dx.doi.org/10.1371/journal.pbio.0050196

Rutte, C., \& Taborsky, M. (2007b). The influence of social experience on cooperative behaviour of rats (Rattus norvegicus): Direct vs generalised reciprocity. Behavioral Ecology and Sociobiology, 62, 499-505. http://dx.doi.org/10.1007/s00265-007-0474-3

Sato, N., Tan, L., Tate, K., \& Okada, M. (2015). Rats demonstrate helping behavior toward a soaked conspecific. Animal Cognition, 18, 1039-1047. http://dx.doi.org/10.1007/s10071-015-0872-2

Scassellati, B., Admoni, H., \& Matarić, M. (2012). Robots for use in autism research. Annual Review of Biomedical Engineering, 14, 275-294. http://dx.doi.org/10.1146/annurev-bioeng-071811-150036

Schwartz, L. P., Silberberg, A., Casey, A. H., Kearns, D. N., \& Slotnick, B. (2017). Does a rat release a soaked conspecific due to empathy? Animal Cognition, 20, 299-308. http://dx.doi.org/10.1007/s10071-016-1052-8

Shi, Q., Ishii, H., Kinoshita, S., Konno, S., Takanishi, A., Okabayashi, S., . . Kimura, H. (2013). A rat-like robot for interacting with real rats. Robotica, 31, 1337-1350. http://dx.doi.org/10.1017/s0263574713000568

Shi, Q., Ishii, H., Kinoshita, S., Takanishi, A., Okabayashi, S., Iida, N., . . Shibata, S. (2013). Modulation of rat behaviour by using a rat-like robot. Bioinspiration \& Biomimetics, 8,046002 . http://dx.doi.org/ 10.1088/1748-3182/8/4/046002

Shi, Q., Ishii, H., Miyagishima, S., Konno, S., Fumino, S., Takanishi, A., . . Kimura, H. (2011). Development of a hybrid wheel-legged mobile robot WR-3 designed for the behavior analysis of rats. Advanced Robotics, 25, 2255-2272. http://dx.doi.org/10.1163/016918611x603819

Shi, Q., Ishii, H., Tanaka, K., Sugahara, Y., Takanishi, A., Okabayashi, S., . . Fukuda, T. (2015). Behavior modulation of rats to a robotic rat in multi-rat interaction. Bioinspiration \& Biomimetics, 10, 056011. http://dx.doi.org/10.1088/1748-3190/10/5/056011

Sober, E., \& Wilson, D. S. (1998). Unto others: The evolution and psychology of unselfish behavior. Cambridge, MA: Harvard University Press.

Tanaka, F., Cicourel, A., \& Movellan, J. R. (2007). Socialization between toddlers and robots at an early childhood education center. Proceedings of the National Academy of Sciences, 104, 17954-17958. http://dx.doi.org/10.1073/pnas.0707769104

Thomas, F. \& Johnston, O. (1995). The illusion of life: Disney animation. Hyperion, New York.

Trivers, R. (1971). The evolution of reciprocal altruism. Quarterly Review of Biology, 46, 35-57. http://dx.doi:10.1086/406755.

Vasconcelos, M., Hollis, K., Nowbahari, E., \& Kacelnik, A. (2012). Pro-sociality without empathy. Biology Letters, 8, 910-912. http://dx.doi.org/10.1098/rsbl.2012.0554

Veling, L. (2017). Becoming real: An anthropological approach to evaluating robots in the real world. Social Robotics Lecture Notes in Computer Science, 638-646. http://dx.doi.org/10.1007/978-3-319-70022-9_63

Watanabe, T., Takezawa, M., Nakawake, Y., Kunimatsu, A., Yamasue, H., Nakamura, M., ... Masuda, N. (2014). Two distinct neural mechanisms underlying indirect reciprocity. Proceedings of the National Academy of Sciences, 111, 3990-3995. http://dx.doi.org/10.1073/pnas.1318570111

Wiles, J., Heath, S., Ball, D., Quinn, L., \& Chiba, A. (2012). Rat meets iRat. 2012 IEEE International Conference on Development and Learning and Epigenetic Robotics (ICDL). doi:10.1109/devlrn.2012.6400870.

Wilkinson, G. S. (1984). Reciprocal food sharing in the vampire bat. Nature, 308, 181-184. http://dx.doi.org/10.1038/308181a0

Wrighten, S., \& Hall, C. (2016). Support for altruistic behavior in rats. Open Journal of Social Sciences, 4, 93-102. http://dx.doi.org/10.4236/jss.2016.412009 
Yamamoto, S., Humle, T., \& Tanaka, M. (2013). Basis for cumulative cultural evolution in chimpanzees: Social learning of a more efficient tool-use technique. PLOS ONE, 8(1), e55768.

https://doi.org/10.1371/journal.pone.0055768 